\title{
Palonosetron on Days 1 and 5 Versus Granisetron Daily (Days 1-5) in Germ Cell Tumour Therapy
}

\author{
YUSUKE SHIMURA $^{1,2}$, KOUJI IZUMI $^{3}$, SHINGO ITAI $^{1}$, HIROAKI IWAMOTO $^{3}$, HIROSHI YAEGASHI $^{3}$, \\ YUKIO SUGA ${ }^{2}$, TSUTOMU SHIMADA ${ }^{1}$, ATSUSHI MIZOKAMI ${ }^{3}$ and YOSHIMICHI SAI ${ }^{1}$ \\ ${ }^{1}$ Department of Hospital Pharmacy, University Hospital, Kanazawa University, Kanazawa, Japan; \\ ${ }^{2}$ Department of Clinical Drug Informatics, Faculty of Pharmacy, Institute of Medical, \\ Pharmaceutical \& Health Sciences, Kanazawa University, Kanazawa, Japan; \\ ${ }^{3}$ Department of Integrative Cancer Therapy and Urology, \\ Kanazawa University Graduate School of Medical Science, Kanazawa, Japan
}

\begin{abstract}
Background/Aim: The control of chemotherapyinduced nausea and vomiting during bleomycin, etoposide, and cisplatin (BEP) treatment is important for maintaining treatment intensity. The effects of palonosetron and granisetron were compared in BEP chemotherapy. Patients and Methods: The administration of palonosetron on days 1 and 5 (Pal method) and granisetron daily (days 1-5, Gra method) were compared in terms of their efficacy and costeffectiveness. Results: Additional rescue antiemetic agents were used in 15 of 32 and 30 of 30 cycles in the Pal and Gra method groups, respectively $(p<0.05)$. The complete response rate, defined as no vomiting and no rescue agent usage, in each cycle, was $50 \%$ and $0 \%$ in the Pal and Gra method groups, respectively $(p<0.05)$. The average cost of antiemetic agents in a cycle was 50,759 and 54,555 yen in the Pal and Gra method groups, respectively $(p<0.05)$. Conclusion: The Pal method may be the standard method in BEP.
\end{abstract}

Germ cell tumour (GCT) is the most common malignancy among adolescents and young adult men (1). The tri-weekly combination therapy of bleomycin on days 1,8 , and 15 (or days 2,9 , and 16 ), etoposide on days $1-5$, and cisplatin on days 1-5 (BEP) is the standard protocol of care for patients with advanced GCT, and BEP can cure GCT completely in the

This article is freely accessible online.

Correspondence to: Kouji Izumi, Department of Integrative Cancer Therapy and Urology, Kanazawa University Graduate School of Medical Science, 13-1 Takara-machi, Kanazawa, Ishikawa 9208641, Japan. Tel: +81 762652393, Fax: +81 762344263, e-mail: azuizu2003@yahoo.co.jp

Key Words: Germ cell tumour, granisetron, palonosetron, chemotherapyinduced nausea and vomiting. majority of patients if treatment is performed appropriately (2). According to risk classification, three or four cycles of BEP, without a delay in the schedule or a dose reduction, are necessary to obtain the expected effect for advanced GCT as the standard of care (3-5); therefore, supportive treatment for adverse events of BEP is important for appropriate treatment.

Cisplatin is classified as a highly emetic risk agent (6), and a high incidence of chemotherapy-induced nausea and vomiting (CINV) is reported in BEP (7). The administration of $5-\mathrm{HT}_{3}$ receptor antagonist in addition to dexamethasone and NK1 receptor antagonist is required during BEP for the prevention of CINV (6). The first generation $5-\mathrm{HT}_{3}$ receptor antagonist, granisetron (Gra), has a short half-life period (8); therefore, daily administration of Gra (days 1-5) is required for the prevention of CINV in BEP. Importantly, CINV in BEP exhibits biphasic peaks; the first and second peak develop after 6-8 and 48-72 $\mathrm{h}$ following cisplatin administration, respectively (9-11). As a second-generation 5- $\mathrm{HT}_{3}$ receptor antagonist, palonosetron (Pal) has a longer half-life period than Gra (12); Pal administration on days 1 and 5 is considered reasonable for the prevention of both acute and delayed CINV.

In the present study, the two generation $5-\mathrm{HT}_{3}$ receptor antagonists $\mathrm{Pal}$ and Gra were compared in terms of their efficacy and cost-effectiveness in BEP for GCT.

\section{Patients and Methods}

Study population. Patients with advanced GCT who underwent BEP at Kanazawa University Hospital between January 2010 and March 2016 were selected and reviewed using their retrospective charts. The present study was performed after receiving approval from the Medical Ethics Committee of Kanazawa University (protocol no. 2015-182).

Protocols of chemotherapy. BEP was administered using previously reported protocols; briefly, cisplatin $\left(20 \mathrm{mg} / \mathrm{m}^{2} /\right.$ day $)$ and etoposide $\left(100 \mathrm{mg} / \mathrm{m}^{2} /\right.$ day) were administered between days 1 and 5 , and 
bleomycin (30 mg/body/day) was administered on days 1,8 , and 15 every 3 weeks (5). The basic antiemetic $5-\mathrm{HT}_{3}$ receptor antagonists were administered using two methods as follows: $0.75 \mathrm{mg}$ Pal was administered intravenously on days 1 and 5 once daily (Pal method) and $3 \mathrm{mg}$ Gra was administered intravenously between days 1 and 5 twice a day (Gra method). As additional basic antiemetic agents, aprepitant (an NK1 receptor antagonist) was administered orally as follows: $125 \mathrm{mg}$ on days $1,80 \mathrm{mg}$ between days 2 and 5 once a day, and $10 \mathrm{mg}$ metoclopramide administered intravenously between days 1 and 5 twice a day. Using the Pal method, $6.6 \mathrm{mg}$ dexamethasone was administered intravenously between days 1 and 5 once a day; using the Gra method, $6.6 \mathrm{mg}$ dexamethasone was administered intravenously on day 1 once a day, followed by $3.3 \mathrm{mg}$ administered between days 2 and 6 once a day. In the present study, two patients in the Gra method group did not take oral aprepitant on days 4 and 5, and one patient in the Gra method group underwent treatment with 6.6 $\mathrm{mg}$ dexamethasone intravenously between days 1 and 5 once a day.

Definition and outcomes. The patients were classified into three risk groups by International Germ Cell Consensus Classification (IGCCC) (3). Complete response (CR) to 5- $\mathrm{HT}_{3}$ receptor antagonists was defined as no vomiting and no additional rescue usage of antiemetic agents in each cycle of BEP. From the commencement of BEP, 0-120, 121-216, and 0-216 h were defined as the acute, delayed, and overall period, respectively, as previously reported (13). The cost of the antiemetic agents was also calculated using Japanese currency, Yen.

Statistical analysis. All statistical analyses were performed in GraphPad Prism 6, using Fisher's exact test, Chi-squared test and Mann-Whitney $U$-test. A $p$-value $<0.05$ was considered statistically significant.

\section{Results}

Patients' characteristics. The Pal and Gra methods were examined in nine patients, respectively. The total number of administration cycles in the Pal and Gra groups was 32 and 30, respectively. Patients' characteristics, including age, smoking and drinking history, clinical stage, and IGCCC risk group, did not differ significantly between the two methods (Table I).

$C R$ rates. The $\mathrm{CR}$ rates in each period and cycle are shown in Figure 1. The CR rate in the Pal method was significantly higher than that in the Gra method in all periods (Figure 1A, $p<0.0001)$. The $\mathrm{CR}$ rate in the $\mathrm{Pal}$ method was significantly higher than that in the Gra method in the first and second cycles ( $p=0.0090$, respectively); however, there was no significant difference between the two methods in the latter half of treatment (third and fourth cycles) (Figure 1B). Of the nine patients in each method, vomiting was recorded in four patients in the Pal method group and in six patients in the Gra method group ( $p=0.6372$, Figure 2A). Additional rescue antiemetic agents were administered in 15/32 cycles in the Pal method and 30/30 cycles in the Gra method; use of the Pal method significantly reduced the use of rescue
Table I. Characteristics.

\begin{tabular}{lccc}
\hline Characteristic & Pal method & Gra method & $p$-Value \\
\hline $\mathrm{n}$ & 9 & 9 & \\
Total cycle number & 32 & 30 & \\
Median age (range) & $30(19-44)$ & $40(17-69)$ & 0.0891 \\
Smoking history & & & \\
$\quad$ Yes & 5 & 4 & 1.0000 \\
$\quad$ No & 4 & 5 & \\
Drinking history & & & \\
Yes & 5 & 4 & 0.5738 \\
No & 4 & 4 & \\
Unknown & 0 & 1 & \\
Stage & 3 & 5 & 0.3428 \\
2 & 6 & 4 & \\
3 & 3 & 6 & 0.3329 \\
IGCCC group & 3 & 1 & \\
$\quad$ Good & 3 & 2 & \\
Intermediate & & & \\
Poor & & &
\end{tabular}

Pal: Palonosetron; Gra: granisetron; IGCCC: International Germ Cell Consensus Classification.

Table II. Cycle numbers with additional agents for rescue.

\begin{tabular}{lcc}
\hline & Pal method, $\mathrm{n}(\%)$ & Gra method, $\mathrm{n}(\%)$ \\
\hline Total cycle number & 32 & 30 \\
Metoclopramide & $8(25)$ & $3(10)$ \\
Domperidone & $7(22)$ & $15(50)$ \\
Prochlorperazine & $5(16)$ & $0(0)$ \\
Dexamethasone & $2(6)$ & $0(0)$ \\
Lorazepam & $0(0)$ & $25(83)$ \\
Alprazolam & $3(9)$ & $0(0)$ \\
Diazepam & $2(6)$ & $0(0)$ \\
Hydroxyzine & $3(9)$ & $0(0)$ \\
Famotidine & $0(0)$ & $5(17)$ \\
Lansoprazole & $3(9)$ & $4(13)$ \\
Rebamipide & $3(9)$ & $0(0)$ \\
Ramosetron & $2(6)$ & $30(100)$ \\
Rikkunshito & $6(19)$ & $0(0)$ \\
\hline
\end{tabular}

Pal: Palonosetron; Gra: granisetron.

antiemetic agents $(p<0.0001$, Figure 2B). The additional rescue agents are shown in Table II.

Total cost of antiemetic agents. The cost of the basic antiemetic agents per cycle in the Pal and Gra methods was 49,661 and 49,807 yen, respectively. The total cost of antiemetic agents, including additional rescue agents per cycle, in the Pal and Gra methods was 50,759 and 54,555 yen, respectively. The cost of the overall antiemetic agents was higher with the Gra method than with the Pal method $(p=0.0005)$. 

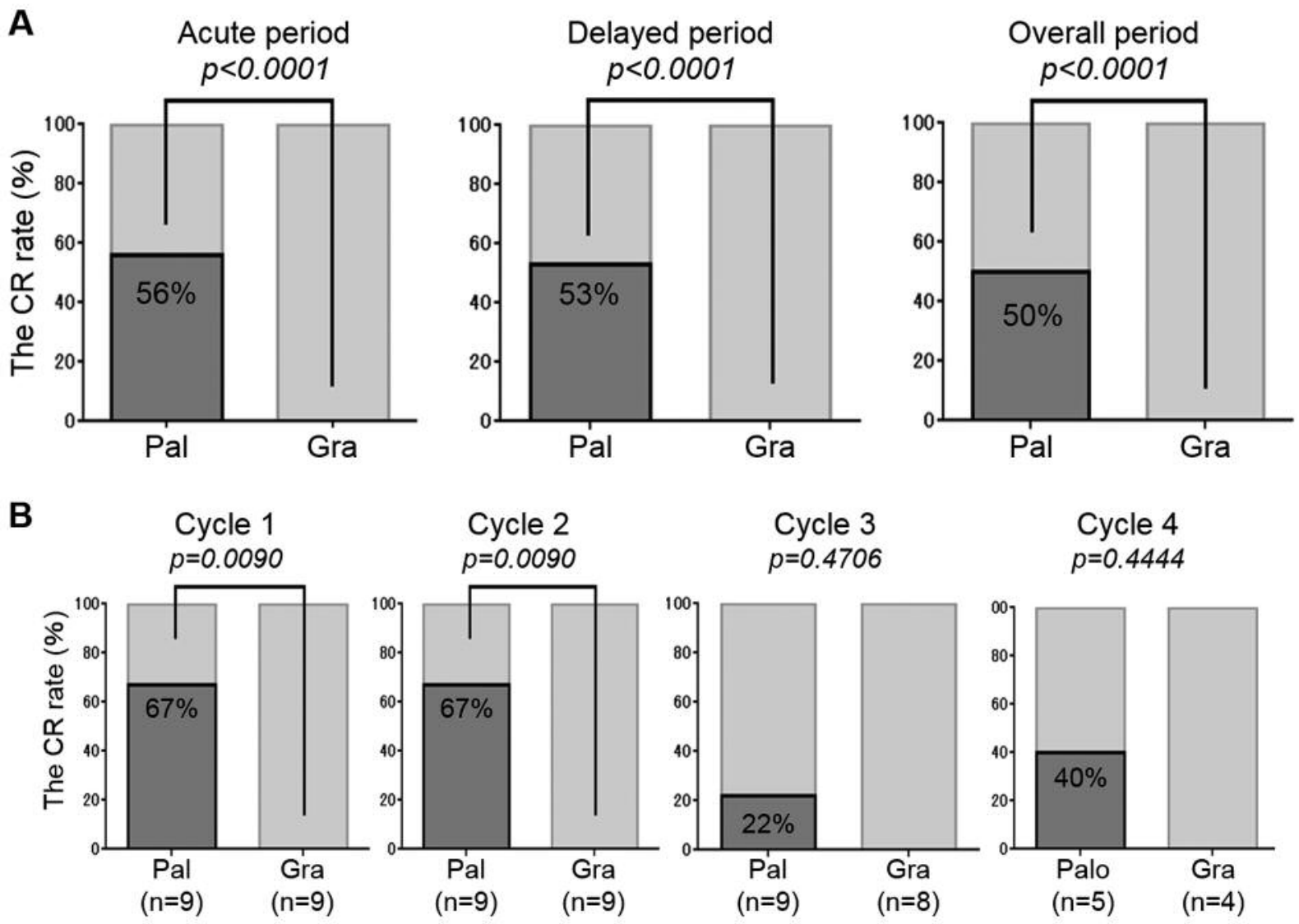

Figure 1. The CR rates in each period and each cycle. (A) CR rates in the Pal (32 cycles) and Gra (30 cycles) methods in each period were compared. (B) CR rates in the Pal (nine patients) and Gra (nine patients) methods in each cycle of BEP chemotherapy were compared. Pal: Palonosetron; Gra: granisetron; BEP: bleomycin, etoposide, and cisplatin; CR: complete response.

\section{Discussion}

In previous studies comparing Pal and Gra, the $\mathrm{CR}$ rates in patients treated with $\mathrm{Pal}$ were reported to be higher than in those treated with Gra (14). However, this study mainly included patients with lung and breast cancer, rather than patients with GCT undergoing unique BEP chemotherapy with cisplatin $20 \mathrm{mg} / \mathrm{m}^{2} /$ day between days 1 and 5 . Einhorn et al. reported that the CR rate for nausea and vomiting was $34.1 \%$ in the acute period and $61.0 \%$ in the delayed period when Pal was administered every other day in 41 patients with GCT (15). Adra et al. also reported that the CR rate was $29.6 \%$ in the acute period and $46.3 \%$ in the delayed period when Pal was administered every other day in 54 patients with GCT (16). However, there is no report comparing the efficacy between first- and secondgeneration $5-\mathrm{HT}_{3}$ receptor antagonists in BEP chemotherapy. Therefore, the present study investigated the efficacy and cost-effectiveness of the Pal method in BEP chemotherapy.
Since Pal has a longer half-life period and a higher affinity for the $5-\mathrm{HT}_{3}$ receptor than first-generation $5-\mathrm{HT}_{3}$ receptor antagonists (17), the administration of $\mathrm{Pal}$ on day 5 is considered reasonable for reducing delayed nausea and vomiting due to its sustained $5-\mathrm{HT}_{3}$ receptor occupancy. Emetic episodes increase in accordance with an increase in the cycle number of chemotherapy, even under administration of the same antiemetic agents (18). The efficacy of the antiemetic agents in the present study also tended to decrease in the latter half of the treatment period (following the third cycle). Repeated chemotherapy and the accumulation of antiemetic treatment may be the reason for weakening of the effect of antiemetic agents. As intermediate and poor prognostic groups of IGCCC require four cycles of BEP as standard treatment (5), the intensity of antiemetic agents should be retained throughout the four cycles of BEP. The Pal method may exert its efficacy in the latter half of the treatment course.

When high-risk emetic agents, such as cisplatin, are used, it is recommended to administer four types of antiemetic 
A

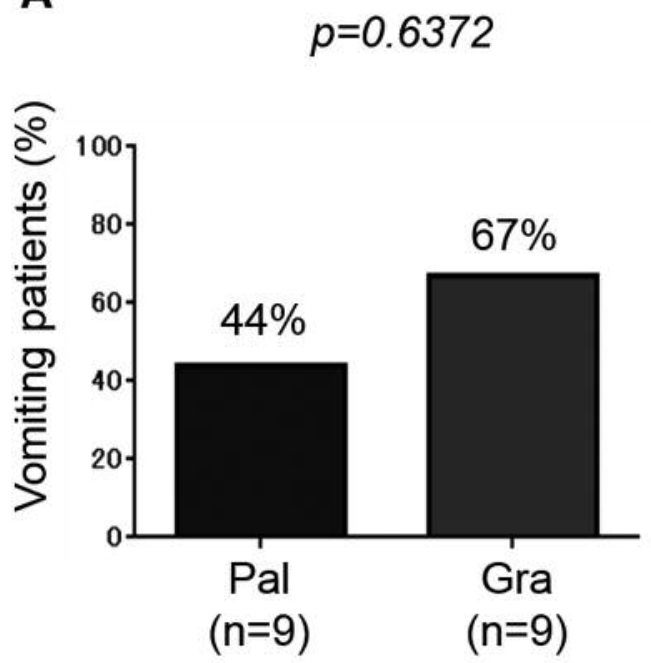

B

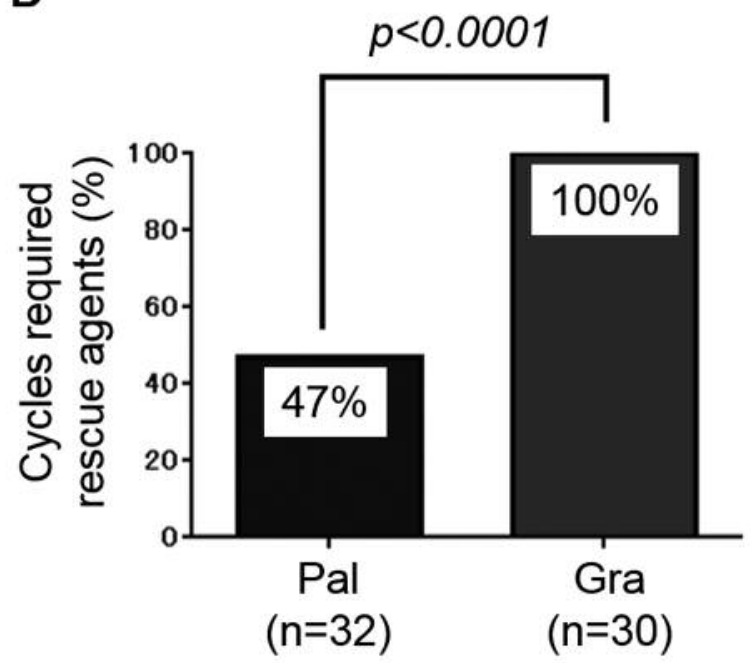

Figure 2. The rate of vomiting patients and cycles required rescue agents. (A) Rates of vomiting patients in the Pal (nine patients) and Gra (nine patients) method throughout chemotherapy was compared. (B) Rates of cycles requiring rescue agents in the Pal (32 cycles) and Gra (30 cycles) methods were compared. Pal: Palonosetron; Gra: granisetron.

agents, 5- $\mathrm{HT}_{3}$ receptor antagonist, dexamethasone, NK1 receptor antagonist, and olanzapine that was added to an updated American Society of Clinical Oncology Clinical Practice Guideline (6). Although the present study suggested the usefulness of the three-agent combination in BEP, the cost of this antiemetic agent combination in a daily low-dose cisplatin regimen has not been assessed in detail. The cost of treatment is one of the important factors for patients under continued treatment, in addition to the efficacy. When the Gra method was compared with the Pal method in the present study, the Gra method was more expensive than the Pal method, not only due to the $5-\mathrm{HT}_{3}$ antagonist but also due to the overall antiemetic agents used (including rescue agents). This result may be applicable to other protocols similar to BEP, including etoposide, ifosfamide, and cisplatin; vinblastine, ifosfamide, and cisplatin; and paclitaxel, ifosfamide, and cisplatin (19-21).

The present study is the first to report that the administration of Pal on days 1 and 5 was superior to daily Gra in BEP chemotherapy in terms of cost-effectiveness data; however, the study had certain limitations. Firstly, this was a retrospective study with a small sample size, and all patients were Japanese. Accumulation of evidence is required due to the incidence rate of GCT being relatively rare. Second, in terms of the basic antiemetic schedule in each method, the dosage of dexamethasone in the Gra method was approximately $70 \%$ compared to that in the Pal method. The influence of the difference in dexamethasone dosage between the two methods cannot be excluded. In addition, the usage of additional antiemetic agents was determined by each physician in charge. Finally, although vomiting was analyzed, nausea was not considered. It is necessary to analyze the frequency and grade of nausea to assess the results correctly. Large prospective studies, including patients of different ethnicities, are required to validate the results of the present study.

\section{Conflicts of Interest}

The Authors declare that they have no conflicts of interest.

\section{Authors' Contributions}

Y. Shimura wrote the initial draft of the manuscript and contributed to analysis and interpretation of data. K. Izumi designed the study, contributed to analysis and interpretation of data, assisted in the preparation of the manuscript, and supervise all process. All other Authors have contributed to data collection and interpretation, and critically reviewed the manuscript.

\section{References}

1 Cheng L, Albers P, Berney DM, Feldman DR, Daugaard G, Gilligan $\mathrm{T}$ and Looijenga LHJ: Testicular cancer. Nat Rev Dis Primers 4: 29, 2018. PMID: 30291251, DOI: 10.1038/s41572-0180029-0

2 van Dijk MR, Steyerberg EW and Habbema JD: Survival of non-seminomatous germ cell cancer patients according to the IGCC classification: An update based on meta-analysis. Eur J Cancer 42: 820-826, 2006. PMID: 16574403, DOI: 10.1016/ j.ejca.2005.08.043 
3 International Germ Cell Consensus Classification: a prognostic factor-based staging system for metastatic germ cell cancers. International Germ Cell Cancer Collaborative Group. J Clin Oncol 15: 594-603, 1997. PMID: 9053482, DOI: 10.1200/JCO.1997. 15.2.594

4 de Wit R, Roberts JT, Wilkinson PM, de Mulder PH, Mead GM, Fosså SD, Cook P, de Prijck L, Stenning S and Collette L: Equivalence of three or four cycles of bleomycin, etoposide, and cisplatin chemotherapy and of a 3- or 5-day schedule in goodprognosis germ cell cancer: a randomized study of the European Organization for Research and Treatment of Cancer Genitourinary Tract Cancer Cooperative Group and the Medical Research Council. J Clin Oncol 19: 1629-1640, 2001. PMID: 11250991, DOI: $10.1200 / \mathrm{JCO} .2001 .19 .6 .1629$

5 Williams SD, Birch R, Einhorn LH, Irwin L, Greco FA and Loehrer PJ: Treatment of disseminated germ-cell tumors with cisplatin, bleomycin, and either vinblastine or etoposide. N Engl J Med 316: 1435-1440, 1987. PMID: 2437455, DOI: 10.1056/NEJM198706043162302

6 Hesketh PJ, Kris MG, Basch E, Bohlke K, Barbour SY, Clark-Snow RA, Danso MA, Dennis K, Dupuis LL, Dusetzina SB, Eng C, Feyer PC, Jordan K, Noonan K, Sparacio D, Somerfield MR and Lyman GH: Antiemetics: American Society of Clinical Oncology Clinical Practice Guideline Update. J Clin Oncol 35: 3240-3261, 2017 PMID: 28759346, DOI: 10.1200/J CO.2017.74.4789

7 Hinton S, Catalano PJ, Einhorn LH, Nichols CR, David Crawford E, Vogelzang N, Trump D and Loehrer PJ Sr: Cisplatin, etoposide and either bleomycin or ifosfamide in the treatment of disseminated germ cell tumors: final analysis of an intergroup trial. Cancer 97: 1869-1875, 2003. PMID: 12673712, DOI: $10.1002 /$ cncr.11271

8 Addelman M, Erlichman C, Fine S, Warr D and Murray C: Phase I/II trial of granisetron: a novel 5-hydroxytryptamine antagonist for the prevention of chemotherapy-induced nausea and vomiting. J Clin Oncol 8: 337-341, 1990. PMID: 2153767 , DOI: $10.1200 / J C O .1990 .8 .2 .337$

9 Kris MG, Gralla RJ, Clark RA, Tyson LB, O'Connell JP, Wertheim MS and Kelsen DP: Incidence, course, and severity of delayed nausea and vomiting following the administration of high-dose cisplatin. J Clin Oncol 3: 1379-1384, 1985. PMID: 4045527, DOI: $10.1200 / \mathrm{JCO} .1985 .3 .10 .1379$

10 Hesketh P: Management of cisplatin-induced delayed emesis. Oncology 53: 73-77, 1996. PMID: 8692555

11 Martin M: The severity and pattern of emesis following different cytotoxic agents. Oncology 53: 26-31, 1996. PMID: 8692547

12 Maemondo M, Masuda N, Sekine I, Kubota K, Segawa Y, Shibuya M, Imamura F, Katakami N, Hida T and Takeo S; PALO Japanese Cooperative Study Group: A phase II study of palonosetron combined with dexamethasone to prevent nausea and vomiting induced by highly emetogenic chemotherapy. Ann Oncol 20: 18601866, 2009. PMID: 19561037, DOI: 10.1093/annonc/mdp195

13 Hamada S, Hinotsu S, Kawai K, Yamada S, Narita S, Kamba T, Nishiyama H, Arai Y, Habuchi T, Ogawa O and Kawakami K: Antiemetic efficacy and safety of a combination of palonosetron, aprepitant, and dexamethasone in patients with testicular germ cell tumor receiving 5-day cisplatin-based combination chemotherapy. Support Care Cancer 22: 2161-2166, 2014. PMID: 24652048, DOI: 10.1007/s00520-014-2182-7
14 Saito M, Aogi K, Sekine I, Yoshizawa H, Yanagita Y, Sakai H, Inoue K, Kitagawa C, Ogura T and Mitsuhashi S: Palonosetron plus dexamethasone versus granisetron plus dexamethasone for prevention of nausea and vomiting during chemotherapy: a double-blind, double-dummy, randomised, comparative phase III trial. Lancet Oncol 10: 115-124, 2009. PMID: 19135415, DOI: 10.1016/S1470-2045(08)70313-9

15 Einhorn LH, Brames MJ, Dreicer R, Nichols CR, Cullen MT, Jr. and Bubalo J: Palonosetron plus dexamethasone for prevention of chemotherapy-induced nausea and vomiting in patients receiving multiple-day cisplatin chemotherapy for germ cell cancer. Support Care Cancer 15: 1293-1300, 2007. PMID: 17436025, DOI: 10.1007/s00520-007-0255-6

16 Adra N, Albany C, Brames MJ, Case-Eads S, Johnson CS, Liu Z, Fausel CA, Breen T, Hanna NH, Hauke RJ, Picus J and Einhorn LH: Phase II study of fosaprepitant $+5 \mathrm{HT}_{3}$ receptor antagonist+dexamethasone in patients with germ cell tumors undergoing 5-day cisplatin-based chemotherapy: A Hoosier Cancer Research Network study. Support Care Cancer 24: 2837-2842, 2016. PMID: 26838019, DOI: 10.1007/s00520-016-3100-y

17 Rojas C, Raje M, Tsukamoto T and Slusher BS: Molecular mechanisms of 5-HT(3) and $\mathrm{NK}(1)$ receptor antagonists in prevention of emesis. Eur J Pharmacol 722: 26-37, 2014. PMID: 24184669, DOI: 10.1016/j.ejphar.2013.08.049

18 Soukop M: Management of cyclophosphamide-induced emesis over repeat courses. Oncology 53: 39-45, 1996. PMID: 8692549

19 Nichols CR, Catalano PJ, Crawford ED, Vogelzang NJ, Einhorn LH and Loehrer PJ: Randomized comparison of cisplatin and etoposide and either bleomycin or ifosfamide in treatment of advanced disseminated germ cell tumors: an Eastern Cooperative Oncology Group, Southwest Oncology Group, and Cancer and Leukemia Group B Study. J Clin Oncol 16: 1287-1293, 1998. PMID: 9552027, DOI: 10.1200/JCO.1998.16.4.1287

20 McCaffrey JA, Mazumdar M, Bajorin DF, Bosl GJ, Vlamis V and Motzer RJ: Ifosfamide- and cisplatin-containing chemotherapy as first-line salvage therapy in germ cell tumors: response and survival. J Clin Oncol 15: 2559-2563, 1997. PMID: 9215825, DOI: 10.1200/JCO.1997.15.7.2559

21 Kondagunta GV, Bacik J, Donadio A, Bajorin D, Marion S, Sheinfeld J, Bosl GJ and Motzer RJ: Combination of paclitaxel, ifosfamide, and cisplatin is an effective second-line therapy for patients with relapsed testicular germ cell tumors. J Clin Oncol 23: 6549-6555, 2005. PMID: 16170162, DOI: 10.1200/ JCO.2005.19.638
Received January 4, 2019

Revised January 28, 2019

Accepted January 29, 2019 